\title{
Mentally abnormal offenders: manner of death
}

\author{
GRAHAM ROBERTSON
}

\begin{abstract}
A 23 year follow up of deaths in a population of mentally disordered patients was carried out, and a typical case history is reported. A quarter (71) of the deaths reported were unnatural, verdicts of suicide or accidental death or open verdicts having been recorded. For men in most age groups the proportion of deaths by suicide was two to three times greater than in the general population in 1982; the rate among those aged 25-29 was five times that in the general population. Differences in the rate of unnatural death among diagnostic categories of mental illness were not significant, but the proportion of unnatural deaths among the mentally handicapped will probably eventually be lower than that among psychotic offenders or those with personality disorders. Violent death occurs at an older age in those with affective disorders.

Social isolation and alienation add to the handicap of mental disorder in this group of people, and these sometimes difficult but always vulnerable patients must continue to be offered asylum other than prison.
\end{abstract}

\section{Introduction}

I present the results of a 23 year follow up of deaths among a population of mentally disordered offenders. Beginning in April 1963, Walker and McCabe collected data on all convicted offenders given hospital orders over 12 months. ${ }^{1}$ Their chief interest was the operation of the then new 1959 Mental Health Act. The population comprised the largest group of mentally disordered offenders studied in England and Wales and formed the basis for a 15 year follow up of the criminal careers of mentally abnormal offenders. ${ }^{24}$ As part of the follow up study information about deaths was supplied by the National Health Service register in Southport and the population was "flagged" so that subsequent deaths could be identified. At the same time the population was added to by 184 patients who had been transferred from prison to hospital after sentence. By the end of 1986 over 300 mentally disordered offenders had died, and the nature of their deaths is the subject of this report.

\section{Methods and results}

The National Health Service register in Southport receives notification of all deaths registered in the United Kingdom. Registration and notification occur within a few days of death; both date and cause of death are noted. This information was added to the data obtained in the earlier studies, and as far as was known the record was complete to the end of 1986. The population comprised 1428 people, of whom 81 were discounted because of inadequate information. Of the remaining $1347,312(23 \%)$ had died.

Table I shows details of the type of death by diagnostic category of mental illness. The most striking finding was the high proportion of violent deaths among the group as a whole ( 71 cases, $25 \%$ ); two people were murdered. Table II shows that in men violent death was associated with young age in both the general population and the group of mentally abnormal offenders. Table III shows the prevalence of suicide by age group in the group of offenders compared with appropriate figures for the general population.

Statistical analysis was carried out by the proportional mortality ratio method described by Fox et al..$^{5}$ The calculation was made only for male

Department of Psychiatry, Institute of Psychiatry, London SE5 8AF GRAHAM ROBERTSON, PHD, lecturer subjects because the number of female subjects who had died was too small for useful comparison. Table IV gives the results for suicide. The proportional mortality ratio for suicide (International Classification of Diseases E950-959) was 274 (confidence interval 179 to 389), and for all unnatural deaths (E800-999) it was 207 (confidence interval 156 to 266). The expected ratio in both cases was 100 and the differences were significant at the $5 \%$ level. Only two deaths in the group studied were due to road traffic accidents, and when this cause of death was removed from the figures for the general population the proportional mortality ratio for all violent deaths increased to 296, almost three times the expected value. A standardised mortality ratio was also calculated, but the confidence interval was wide (957 to 2086) because of the very small number of expected deaths from suicide (1-84). For information, the standardised mortality ratio for suicide in the population studied was 1467. In tables II-IV the figures for the general population were taken from statistics for 1982 as the percentage of deaths by suicide in that year corresponded to the average for the period of the study (see below). ${ }^{6}$

\section{Case report}

Statistics tell one side of the story but cannot reflect the misery wrought by these illnesses on the patients and their families. One man was in his late 40s

TABLE I-Type of death by diagnostic category of 283 mentally abnormal offenders. Values are numbers (\%)

\begin{tabular}{|c|c|c|c|c|c|}
\hline \multirow[b]{2}{*}{ Type of death } & \multicolumn{4}{|c|}{ Diagnostic category } & \multirow[b]{2}{*}{ Total } \\
\hline & Schizophrenia & $\begin{array}{l}\text { Affective } \\
\text { psychoses }\end{array}$ & $\begin{array}{c}\text { Mental } \\
\text { handicap }\end{array}$ & Other & \\
\hline \multicolumn{6}{|c|}{ Natural death } \\
\hline $\begin{array}{l}\text { Cancer } \\
\text { Respiratory diseases } \\
\text { Heart diseases } \\
\text { Other }\end{array}$ & $\begin{array}{l}26(18) \\
27(19) \\
37(26) \\
14(10)\end{array}$ & $\begin{array}{c}4(10) \\
13(33) \\
12(30) \\
3(8)\end{array}$ & $\begin{array}{r}8(17) \\
10(21) \\
11(23) \\
10(21)\end{array}$ & $\begin{array}{r}9(17) \\
8(15) \\
14(27) \\
6(12)\end{array}$ & $\begin{array}{l}47(17) \\
58(20) \\
74(26) \\
33(12)\end{array}$ \\
\hline Total & $104(73)$ & $32(80)$ & $39(81)$ & $37(71)$ & $212(75)$ \\
\hline \multicolumn{6}{|c|}{ Violent death } \\
\hline $\begin{array}{l}\text { Suicide } \\
\text { Accident or open verdict }\end{array}$ & $\begin{array}{l}19(13) \\
20(14)\end{array}$ & $\begin{array}{l}7(17) \\
1(2)\end{array}$ & $\begin{array}{l}2(4) \\
7(14)\end{array}$ & $\begin{array}{l}6(12) \\
9(17)\end{array}$ & $\begin{array}{l}34(12) \\
37(13)\end{array}$ \\
\hline Total & $39(27)$ & $8(20)$ & $9(19)$ & $15(29)$ & $71(25)$ \\
\hline Total No of deaths & 143 & 40 & 48 & 52 & $283^{\star}$ \\
\hline
\end{tabular}

$\star 312$ Notifications of death were received; information on type of death was not available for 29 people.

TABLE II-Number (\%) of violent deaths among male mentally abnormal offenders by age at death compared with percentage of violent deaths, including and excluding road traffic accidents, among men and boys in the general population in 1982

\begin{tabular}{lccc}
\hline & \multicolumn{2}{c}{ \% In general population in 1982* } \\
\cline { 3 - 4 } Age (years) & $\begin{array}{c}\text { Mentally abnormal } \\
\text { offenders }\end{array}$ & $\begin{array}{c}\text { Including } \\
\text { road traffic } \\
\text { accidents }\end{array}$ & $\begin{array}{c}\text { Excluding } \\
\text { road traffic } \\
\text { accidentst }\end{array}$ \\
\hline$\leqslant 19$ & $1 / 1(100)$ & 25 & \\
$20-29$ & $12 / 16(75)$ & 52 & 24 \\
$30-39$ & $18 / 28(64)$ & 38 & 28 \\
$40-49$ & $19 / 57(33)$ & 14 & 11 \\
$50-59$ & $7 / 59(12)$ & 5 & 4 \\
$\geqslant 60$ & $4 / 81(5)$ & 2 & \\
\hline Total No & $61 / 242$ & $290166 \ddagger$ & \\
\hline
\end{tabular}

^From mortality statistics. ${ }^{6}$

tCategories E810-819, International Classification of Diseases. $\ddagger$ Total No of men who died in 1982 . 
TABLE III-Number (\%) of deaths by suicide among 242 male mentally abnormal offenders by age at death compared with percentage of deaths by suicide among men and boys in the general population

\begin{tabular}{lcc}
\hline Age (years) & $\begin{array}{c}\text { Mentally abnormal } \\
\text { offenders }\end{array}$ & $\begin{array}{c}\text { \% In general population } \\
\text { in } 1982^{\star}\end{array}$ \\
\hline 519 & $1 / 1(100)$ & 1 \\
$20-29$ & $7 / 16(44)$ & 14 \\
$30-39$ & $9 / 28(32)$ & 13 \\
$40-49$ & $9 / 57(16)$ & 5 \\
$50-59$ & $2 / 59(3)$ & $1 \cdot 7$ \\
$\geqslant 60$ & $0 / 81$ & $0 \cdot 4$ \\
\hline Total & $28 / 242$ & $290166 \dagger$ \\
\hline
\end{tabular}

${ }^{\star}$ From mortality statistics. ${ }^{6}$

tTotal No of men who died in 1982.

TABLE IV-Proportional mortality ratios of suicide for male mentally abnormal offenders by age at death

\begin{tabular}{lllllll}
\hline & \multicolumn{5}{c}{ Age at death (years) } \\
\cline { 2 - 6 } & $20-29$ & $30-39$ & $40-49$ & $50-59$ & $60-69$ \\
\hline (a) Total No of deaths (all causes) & 16 & 28 & 57 & 59 & 43 \\
(b) No of deaths by suicide & 7 & 9 & 9 & 2 & \\
(c) Proportion of deaths expected by suicide & $0 \cdot 141$ & 0.128 & 0.053 & 0.017 & 0.006 \\
(d) Expected No of deaths by suicide $(a) \times(c)$ & $2 \cdot 26$ & 3.58 & 3.02 & 1.00 & 0.25 \\
\hline
\end{tabular}

${ }^{\star}$ From mortality statistics. ${ }^{6}$

when first admitted to mental hospital suffering from depression. Over the next five years he was admitted a further five times, the diagnosis finally being manic depressive psychosis. As the years passed his extremes of mood became more pronounced and his periods of stability fewer; he was either in the depths of an awful despair or behaving wildly. When in the depths of despair he was totally dependent and could not bear to have his wife out of his sight. When manic he drank to excess and abused his wife and children verbally and, on occasions, physically; he was grandiose and incurred debts that his wife had to pay off. From being a loving and caring father he abused his wife and children for hours, days, or even weeks. He was unpredictable and kept his own hours so that his wife, who had to maintain their home and her job, was kept awake night after night until 3 or 4 am by a never ceasing flow of invective. She coped with this for eight years.

When in hospital he sometimes behaved in a similar difficult way, threatening to leave and accusing the staff, as he did his wife, of ill treatment. He was placed on section on many occasions, but the system did not always work as quickly as his wife and others would have liked, so that he sometimes succeeded in further foolish spending, accruing more debts, which his wife was ill equipped to meet. None the less, his treatment over this period was mostly excellent; when his mental state and behaviour were such that he was likely to cause harm to himself or others he was detained in hospital until he was better. It did not last: because of his aggressive behaviour when drunk he was eventually barred from the hospițal and, when picked up by the police in central London, had to be taken to another hospital. He was grossly deluded, his mood fluctuating from tearfulness and despair one moment to extreme excitement the next. During the following nine months he alternated between this new hospital and his home, but he became unmanageable, especially at home. He threatened to kill his wife and she became afraid of him. Sometimes she left at night for a place of safety, there being no such place available for her husband. Considerable efforts were made to admit him to hospital during this time but without success, and his family often felt that no one cared.

He finally left home. While his money lasted he lived in small hotels, but he was often homeless, wandering round central London mentally ill. He was soon in trouble with the police. On one occasion he stole a car, although he later informed the police of its whereabouts. The police were almost always sympathetic in their dealings with him, recognising that he required psychiatric help. Their problem, later to be the problem of the courts, was how to arrange for him to obtain help. Within six months after leaving home he was in prison on remand. A cycle of going from hostel to prison to hospital followed, but within a month after discharge from prison he killed himself, as he had threatened, by throwing himself under an approaching train.

Before his death he had told his sons that he could not stand his feelings when he was manic; it was not his depressive feelings but what he did and what he said when unable to control his behaviour that he found unbearable. His illness killed him, just as cancer might have done, but had he suffered from cancer he and his family would have been supported. As he grew more ill he received less support and was rather badly served by the hospital system; this may have been because he had removed himself from his family and its protection as a wife in obvious distress is more likely to evoke a sympathetic response from a hospital than a policeman with a problem on his hands. Certainly, the deterioration in his care coincided with his leaving home.

\section{Discussion}

\section{PREVALENCE OF SUICIDE}

Between 500000 and 600000 deaths are recorded each year in England and Wales. Since 1963 the proportion of deaths by suicide has fluctuated but has never been more than $1 \%$, varying from $0.63 \%$ to $1.00 \%$ with a mean of $0.74 \%$. The proportion varies with age, reaching a high of $12 \%$ among the $25-29$ age group. ${ }^{78}$ The equivalent figure among the mentally disordered group in this study was $67 \%$ (nine cases). As all members of the study group still alive at the end of 1.986 were aged over 30 this figure is final and the difference in the proportions of deaths by suicide between the general population and the study group may be regarded as a measure of the increased risk of suicide among mentally disordered offenders in that age range. As indicated by the figures in table IV, the ratio of observed to expected death by suicide was greater among the offenders by a factor of between two and three, at least until the sixth decade.

\section{SUICIDE AND ACCIDENTAL DEATH}

As the Central Statistical Office points out, the true figures for suicide are probably much higher than those recorded in official statistics because "coroners, who have the responsibility in England and Wales for determining the status of unnatural deaths, have to be satisfied the evidence proves the person took his or her own life before they record a verdict of suicide." A series of studies by Holding and Barraclough found very high rates of psychiatric disorder among those whose deaths had been recorded as accidental or when open verdicts had been returned after inquest. ${ }^{9-11}$ There is good reason, therefore, to group unnatural, violent deaths together, and this practice has been adopted in the remainder of this paper.

Though violent death is considered unnatural, it constitutes the cause of death for more than half of the male subjects who die within the age range $15-25,{ }^{7}$ about $40 \%$ of such deaths being due to road traffic accidents: ${ }^{10}$ No comparison was, however, possible here as only 229 of the $1347(17 \%)$ people in the population of mentally abnormal offenders were under 21 when indexed. The association between type of death and age at death complicates comparative analysis. As the population ages so the proportion of unnatural deaths declines, but given that only 70 of the 1035 (7\%) mentally abnormal offenders alive when the present study was completed were under 40 the association with violent death will probably remain above normal into old age.

\section{DIAGNOSTIC DIFFERENCES}

The overall proportional differences in violent deaths between diagnostic groups of mental illness in this population of offenders was not significant $\left(\chi^{2}=3.97, \mathrm{df}=3\right)$, though a diagnosis of affective psychosis was associated with a verdict of suicide rather than a verdict of accidental death or an open verdict $\left(\chi^{2}=4 \cdot 02, \mathrm{df}=1\right.$, $p<0.05)$. As a history of depressive illness may influence which of these three verdicts is returned by the coroner, ${ }^{11}$ the difference does not necessarily represent a real distinction between the groups in the manner of their dying. The pattern of age at death of those with affective psychosis who died violently differed from that of the other groups in that all eight died after the age of 40 . In contrast, 38 of the $63(60 \%)$ people with schizophrenia, mental handicap, or "other" disorders had died by that age, $18(28 \%)$ by the age of 30 . Mood disorders and suicide are associated clinically. The high rate of violent death among younger subjects with schizophrenia may reflect an often unrecognised affective component in schizophrenia 
or have been due to the earlier onset of this devastating illness. The high rate of violent death among the subjects with "other" disorders reflects the prevalence of disturbance among neurotic patients and those with personality disorders in forensic psychiatric practice.

\section{CONCLUSION}

A quarter of deaths among this population of mentally disordered offenders were violent. As the population ages, the proportion of violent deaths will decrease, but comparison with figures for the general population indicated an increased risk of unnatural death by a factor of between two and three. Death by suicide in the 25 to 29 age range was five times more common among the study population than the general population. Violent death was not statistically associated with diagnostic category though was less common among those with affective psychosis and mental handicap. There is good reason to believe that violent death occurs at an older age among those with affective disorders and that the difference in the rate of violent death between the two psychotic groups will diminish as the population ages. The very high rate of violent death among the nonpsychotic group with "other" diagnoses shows the degree of disturbance even when "formal" mental illness is absent.

The likelihood of committing lethal offences is higher than expected in the schizophrenic population but not particularly abnormal among other diagnostic categories of mental illness. ${ }^{12}{ }^{13}$ Even so, the number of schizophrenic people who kill must be much less than $1 \%$. In comparison, this study shows that the risk of violent death to schizophrenic people is enormous, reinforcing the view that the illness renders them much more dangerous to themselves than others.

Serious mental illness carries an increased risk of unnatural death, which is probably exacerbated among mentally abnormal offenders, many of whom are alienated from family and friends, destitute, and unable to find asylum. Ultimately, better under- standing of-and hence better remedies for-many of these illnesses may be forthcoming. In the mean time, as the case presented shows, the mentally disordered who are troublesome or who have forensic histories are liable to be rejected by local hospitals. As more mental hospitals are closed the need for asylum support becomes more pressing and this unpopular but needy group is liable to suffer in consequence. Part of that suffering may be an untimely and lonely death.

This study could not have been completed without the continuing help of the staff at the National Health Service register, Southport. I thank also Professor John Fox of the City University, London, for statistical help and Maureen Bartholomew for typing the manuscript.

\section{References}

1 Walker N, McCabe S. Crime and insanity in England and Wales. Vol 2. Edinburgh: Edinburgh

2 Gibbens TCN, Robertson G. A survey of the criminal careers of hospital order patients. $\mathrm{Br} \mathcal{F}$ Psychiatry 1983;143:362-9.

3 Gibbens TCN, Robertson G. A survey of the criminal careers of restriction order patients. $\mathrm{Br} \mathcal{J}$ Psychiairy 1983;143:370-5.

4 Robertson G, Gibbens TCN. Transfers from prisons to local psychiatric hospitals under section 72 of the 1959 Mental Health Act. BrMed $\mathcal{F}$ 1980;280:1263-6.

Fox J, Gee D, Jones D, Leon D. Cancer and work. London: City University Statistical Laboratory, 1982.

6 Office of Population Censuses and Surveys. Mortality statistics. London: HMSO, 1982. (Series DH2 No 9.)

7 Central Statistical Office: Social trends. London: HMSO, 1982.

8 Central Statistical Office. Annual abstract of statistics. No 123. London: HMSO, 1987.

9 Holding TA, Barraclough BM. Psychiatric morbidity in a sample of a London coroner's open verdicts. Br $\mathcal{F}$ Psychiatry 1975;127:133-43.

10 Holding TA, Barraclough BM. Psychiatric morbidity in a sample of accidents. Br $\mathcal{f}$ Psychiatn 1977;130:244-52.

11 Holding TA, Barraclough BM. Undetermined deaths-suicide or accident? Br $\mathcal{f}$ Psychiatn 1978;133:542-9.

12 Taylor PJ, Gunn J. Violence and psychosis. I. Risk of violence among psychotic men. Br Med $\mathcal{J}$ 1984;288:1945-9.

13 Hafner H, Boker W. Crimes of violence by mentally abnormal offenders. Cambridge: Cambridge University Press, 1973.

(Accepted 23 June 1987)

\section{SHORT REPORTS}

\section{Is endocrine ophthalmopathy related to smoking?}

Endocrine ophthalmopathy is most commonly seen in patients with Graves' disease but is also found in other thyroid disorders and occasionally in patients without any signs of thyroid dysfunction ${ }^{1}$; the factors concerned are poorly understood. Having gained the impression that a history of smoking is common in patients with severe endocrine ophthalmopathy, we conducted a case-control study that documented smoking habits in these patients, patients with Graves' disease with only slight or no eye disease, and subjects without any thyroid disorder.

\section{Patients, methods, and results}

We studied all 12 patients treated in this department during 1972-84 with endocrine ophthalmopathy class 3 or more (Werner's classification) ${ }^{2}$ (10 women, two men; mean age at onset of ophthalmopathy 38 (range 24-51)). Six patients had Graves' hyperthyroidism; two had previously been treated surgically for this disease, one had spontaneous hypothyroidism; and three did not have any known thyroid disorder but did have enlarged extraocular muscles on orbital computed tomography and a reduced response of thyroid stimulating hormone to thyrotrophin releasing hormone. For each proband two control patients with Graves' hyperthyroidism but less severe ophthalmopathy (class 0-2) were matched for sex, age at diagnosis of thyrotoxicosis (within five years), and year of diagnosis. All subjects completed a questionnaire including details of smoking habits. For each proband four controls were randomly selected from a population registry and matched for sex and exact age. Smoking habits for the year of onset of ophthalmopathy in the corresponding proband were asked for; the response rate was $\mathbf{8 8 \%}$. We defined subjects who had been daily smokers for some period during the past year as current smokers and those who had been daily smokers but had not smoked in the past year as ex-smokers.
Mantel-Haenszel odds ratios for matched pairs with $95 \%$ confidence intervals were used to calculate significance ${ }^{3}$; a result was considered to be significant when the confidence interval did not include the value $1 \cdot 0$.

Ten of the 12 patients with endocrine ophthalmopathy (83\%) were current smokers, including all four with loss of vision. This compared with 11 of the 24 (46\%) hyperthyroid patients without severe eye disease and 13 of the $42(31 \%)$ controls.

The figure shows that total tobacco consumption was considerably higher in the patients with endocrine ophthalmopathy than the two other groups. The odds ratio between patients with ophthalmopathy and controls was 20.2 for current smoking ( $95 \%$ confidence interval $2 \cdot 8$ to $144 \cdot 8)$. When ex-smokers and current smokers were analysed together the odds ratio was reduced to $8 \cdot 9(1 \cdot 3$ to $60 \cdot 2)$. The odds ratio between patients with thyroid disease with and without ophthalmopathy was $10 \cdot 0(1 \cdot 4$ to $74 \cdot 3)$ for current smokers and $4 \cdot 5(0 \cdot 8$ to $24 \cdot 3)$ when ex-smokers were included.

\section{Comment}

This study suggests that smoking and severe endocrine ophthalmopathy are associated. A higher proportion of patients with endocrine ophthalmopathy were smokers compared not only with randomly selected controls but also with patients with Graves' disease with slight or no ophthalmopathy. Therefore the main effect of smoking seems to be on the severity of eye disease in Graves' disease. The association was stronger when only current smokers were considered, which suggests that the effect of smoking on endocrine ophthalmopathy is direct and immediate.

An association between smoking and thyroid disease has been observed. ${ }^{4}$ Infiltrative and severe endocrine ophthalmopathy is believed to be of autoimmune origin. ${ }^{1}$ Smoking affects both the cell mediated and the humoral immune systems, but the influence seems to be mainly an inhibitory one. ${ }^{5}$ Possibly subsets of T or B cells are differently affected by 